\title{
A Comparison of Exercise Intensity between Two Horticultural and Four Common Physical Activities among Male Adults in Their 20s
}

\author{
Sin-Ae Park ${ }^{1}$, A-Young Lee ${ }^{1}$, Ho-Sang Lee ${ }^{1}$, Kwan-Suk Lee ${ }^{2}$, and Ki-Cheol Son ${ }^{1 *}$ \\ ${ }^{1}$ Department of Environmental Health Science, Konkuk University, Seoul 143-701, Korea \\ ${ }^{2}$ Department of Industrial Engineering, Hongik University, Seoul 121-791, Korea
}

\begin{abstract}
This study aimed to identify the exercise intensity associated with four common physical activities for adults (running, skipping rope, walking, and muscle strength exercises) and two horticultural activities (creating a vegetable bed and garden maintenance). For this experiment, 19 males (mean age: $25.8 \pm 2.3$ years) randomly participated in the activities at a glasshouse at Konkuk University. Each of the six activities lasted for 5 minutes; the subjects rested for 5 minutes during intervals between the activities. A portable metabolic analyzer was used to store the oxygen and energy consumption values obtained upon measurement of each activity. In addition, a wireless heart rate monitor was used to measure the subjects' heart rate. According to the results, the four types of physical activities and two horticultural activities carried out by the subjects are moderate- to high-intensity activities [i.e., $3.8 \pm 0.9$ to $9.9 \pm 2.1$ metabolic equivalents (METs)]. Running $(9.9 \pm 2.1$ METs) and skipping rope (8.8 \pm 2.2 METs) were categorized as high-intensity physical activities, whereas creating a vegetable bed (5.0 \pm 1.2 METs), walking (4.9 \pm 0.8 METs), muscle strength exercises ( $4.5 \pm 1.3 \mathrm{METs})$, and garden maintenance (3.8 \pm 0.9 METs) were classified as moderate-intensity physical activities. The exercise intensities of horticultural activities in this study were similar to those of walking and muscle strength exercises. Therefore, participating in these horticultural activities is expected to garner health benefits similar to those reaped from the physical activities described in the current study.
\end{abstract}

Additional key words: energy expenditure, horticultural therapy, socio-horticulture, urban agriculture

\section{Introduction}

Physical activities refer to all physical movements accompanied by energy consumption as a result of musculoskeletal contraction (Biddle, 1995; Caspersen et al., 1985). As a measure of physical activity, the amount of energy expended during exercise is quantified; subsequently, the metabolic equivalents (METs), representing the metabolic rate during a specific physical activity, are compared to the resting state. One MET is defined as $\mathrm{O}_{2}$ intake during an at-rest state of $3.5 \mathrm{~mL} \cdot \mathrm{kg}^{-1} \cdot \mathrm{min}^{-1}$ (Jette et al., 1990; Powers and Howley, 2007). METs are categorized according to exercise intensity, namely, sedentary ( $\leq 1.5$ METs), light (1.6-2.9 METs), moderate (3.0-5.9 METs), and vigorous ( $\geq 6.0 \mathrm{METs}$ ) (HHS, 2008a; Pate et al., 2008).
Regular physical activity provides a range of health benefits, including lower risks of chronic disease (e.g., cardiovascular disease, diabetes, cancer, hypertension, obesity, depression, and osteoporosis) or the prevention thereof and premature death, and facilitating improvements in functional ability (Powell et al., 2011; Warburton et al., 2006). In particular, for the health benefits of adults, the United States Department of Health and Human Services recommends more than $150 \mathrm{~min}$ of moderate physical activity (3.0-5.9 METs) a week or more than 75 min of vigorous physical activity (6.0 METs) a week, as well as participation in musclestrengthening activities for two or more days a week (HHS, 2008b).

The mechanism of various physical benefits stemming from engagement in regular physical activities may be

\footnotetext{
*Comesponding author: kcson@konkuk.ac.kr

※ Received 9 May 2014; Revised 20 October 2014; Accepted 23 October 2014. This paper was supported by the SMART Research Professor Program of Konkuk University.

(C) 2015 Korean Society for Horticultural Science
} 
explained in terms of muscle contraction and physical movement, which are key elements of physical activity. Physiological changes in the body reportedly take place as a result of physiological elements such as $\mathrm{O}_{2}$, glucose, and the fat required when energy is consumed to contract muscles with metabolism and neurological elements, thus facilitating physical movement. In particular, aerobic activities facilitate energy consumption that, in turn, forms the basis of physical movements, ultimately facilitating positive changes in the cardiovascular and cellular systems by increasing the capacity and efficiency of $\mathrm{O}_{2}$ and glucose delivery to the appropriate tissues (Powell et al., 2011).

Despite the various health benefits of physical activity, about $31 \%$ of the world population, including Africa (27.5\%), the Americans (43.3\%), the Eastern Mediterranean Region (43.2\%), Europe (34.8\%), Southeast Asia (17.0\%), and the Western Pacific (33.7\%), is physically inactive. This is according to a survey conducted on the global level of physical activity (Hallal et al., 2012). Physical inactivity habits are gradually formed from childhood, spanning to adolescence and adulthood. During childhood, vigorous physical activity is quite common, but decreases during adolescence and early adulthood (Calfas et al., 2000; Caspersen et al., 2000; Stone et al., 1998); then, during adulthood, intermediate physical activities such as walking decrease drastically (Leslie et al., 2001). The main reasons for this sharp decrease in physical activities in adulthood are the increase in sedentary behavior-which accounts for a large proportion of everyday life, such as when using computers and mobile phones, watching television, and resting after work-and perceived time constraints (Mein et al., 2005; NASPE, 2003; Popham and Mitchell, 2006; Warren et al., 2010).

There is a need for a national strategy aimed at increasing the public's participation in physical activities. This can be facilitated through changes in the socio-political and physical environments, which would result in infrastructure development, resource allocation, the fostering of an appropriate environment, and public policies that take into consideration natural factors that can improve adults' participation in physical activity (Brownson et al., 2000; King et al., 1995a; Sallis et al., 1998; Schmid et al., 1995). For sustained participation in physical activities, the motivation to engage in such activities must be developed at an individual level (Kilpatrick et al., 2002). The development of individual motivation involves the replacement of extrinsic motivation with intrinsic motivation. Extrinsic motivation refers to external factors such as compensation, pressure, and physical health. Intrinsic motivation can lead to autonomous behavior resulting from the internalizing of various behavioral factors such as interest, joy, skills development, and the formation of social relationships (Deci and Ryan, 1995; Kilpatrick et al., 2002). Therefore, motivation to participate in physical activities must be developed at both an individual and a national level, so as to sustain participation in abovementioned activities. To this end, individuals must develop an interest in physical activities, as well as experience the joy and establishment of social relationships associated with participation in such activities.

Traditionally, gardening is a popular form of leisure activity in the West (Atwood, 2004). Recently, 'the Act of Developing and Supporting Urban Agriculture' has led to increased interest and participation in gardening activities in South Korea (RDA, 2010). Community gardening not only provides nutritious food and opportunities for social bonds among residents as a result of their collaboration, but also enables social diversity in the community, facilitates vocational training and education, and enhances social capital as well as regional safety and security (Dickinson et al., 2003; Doyle and Krasny, 2003; Ferris et al., 2001; Fusco, 2001; Holland, 2004; Irvine et al., 1999).

Advanced research has revealed that gardening involves low- to high-intensity energy consumption and requires the use of various muscles (Bassett et al., 2000; Brooks et al., 2004; Gunn et al., 2002, 2004; Park et al., 2008a, 2011, 2012, 2013, 2014a). Park et al. (2014a) examined the intensity of 10 gardening activities. Moderate-intensity activities (3.5 \pm 0.5 to $5.4 \pm 1.0 \mathrm{METs}$ ) included planting seedlings, mixing soil, watering, harvesting, sowing seeds, and hoeing, while digging soil was classified as a highintensity physical activity $(6.3 \pm 1.2 \mathrm{METs})$. The intensity of yard work specifically for adults was also determined; trimming and raking were classified as moderate-intensity activities ( $3.53 \pm 0.76$ to $5.95 \pm 1.38$ METs) (Bassett et al., 2000). Moreover, lawn mowing was examined in a laboratory setting and subsequently classified as a moderateintensity activity, at $5.6 \pm 1.0$ and $6.0 \pm 1.0$ METs for 35to 45-year-old Australian adults of both genders, respectively (Brooks et al., 2004; Gunn et al., 2004).

Gardening activities, as a form of physical activity, reportedly provide various health benefits, such as an increase in hand grip strength and a decrease in cholesterol and blood pressure levels (Armstrong, 2000; Kingsley, 2009; Park et al., 2009; Reynolds, 1999; Turner et al., 2002), as well as psychosocial benefits in the form of enhanced self-respect, reduced stress, and increased social interaction (Cammack et al., 2002; Kaplan, 1973; Patel, 1991; Reynolds, 2002; Waliczek et al., 2005; Walsh et al., 2001).

Therefore, this study compared physical activity intensity 
and energy consumption between common physical activities (running, skipping rope, walking, and muscle strength exercises) and gardening activities (creating a vegetable bed and garden maintenance). The results from this study could help determine if gardening can be utilized as a physical activity to lead the same health benefits from non gardening forms of physical activities in adults.

\section{Materials and Methods}

\section{Subjects}

The study sample consisted of 19 male students at Konkuk University, Gwangjin-gu, Seoul. The subjects were required to male, aged in 20s, able to engage in physical activities, and without current physical illness. The subjects were recruited by word of mouth or contacted by telephone after their details were obtained from a volunteer list that they had completed. On the phone, we explained the details regarding the test and provided the test date to candidates who wished to participate in this study. The conditions for participation included avoiding excessive physical activities and over-eating $12 \mathrm{~h}$ before the test, and refraining from alcohol and caffeine consumption. In addition, the subjects were requested to wear comfortable attire for participation in the scheduled gardening and physical activities. Each subject was compensated with 10,000 KRW for participating in this study.

\section{Experimental Procedures and Physical Activities Performed}

The subjects visited the glasshouse at Konkuk University between late June and early July 2013, wherein they performed six activities (two horticultural activities and four common physical activities). The glasshouse had an average temperature of $27.0 \pm 2.4^{\circ} \mathrm{C}$ and a relative humidity of 35.0 $\pm 5.8 \%$ (Model Acuba CS-201, Digital Hygro-Thermometer, Chosun, China). Four common physical activities that reported as a moderate or high intensity physical activity for adults aged 18 to 65 years in the compendium of physical activities by Ainsworth et al. (2011) were selected. Two horticultural activities were consisted of gardening tasks with mostly moderate intensity in adults aged in their 20s as determined in the previous study (Park et al., 2014a) because each horticultural activity is generally a series of horticultural tasks rather than the repetition of the same motion.

The order of the activities was decided on by randomly drawing lots. Each activity was performed for $5 \mathrm{~min}$ and the total test duration was about $60 \mathrm{~min}$. The subjects took a 5 min break between each activity. Before each activity, the researcher provided a detailed explanation on what that activity involved and the method needed to carry it out, so as to ensure consistency among the subjects. The six activities performed by the subjects were as follows.

For running, the subjects ran back and forth along a corridor $(1.2 \times 12 \mathrm{~m})$ inside the glasshouse at an average speed of $8.64 \mathrm{~km} \cdot \mathrm{h}^{-1}$, based on a $1 / 8 \mathrm{rhythm}$ of the metronome application (Metronome; Gismart, Road Town, UK). Skipping rope required subjects to jump over a $2.7 \mathrm{~m}$ skipping rope for $5 \mathrm{~min}$, at an average of $102 \mathrm{skip} / \mathrm{min}$ in a pre-prepared space in the glasshouse. The subjects had the option to rest after running or skipping rope (Town et al., 1980). The walking activity involved subjects walking back and forth in a corridor $(1.2 \times 12 \mathrm{~m})$ inside the glasshouse at an average of $5.79 \mathrm{~km} \cdot \mathrm{h}^{-1}$, with the metronome application (Metronome; Gismart, Road Town, UK) set at a rhythm of $1 / 4$ for 5 min (Hendelman et al., 2000). During the muscle strength exercises, the subjects held dumbbells (1 kg) with both hands and carried out one set of squats, a dumbbell row, and a lateral raise 15 times, respectively, for a period of $5 \mathrm{~min}$ (Miyachi et al., 2010).

When creating a vegetable bed, the subjects had to do so in five stages, which involved moving, mixing, and filling soil, as well as planting seedlings and watering at set times. In the first stage, the subjects had to move soil from a bucket (75 L) into a container for a period of $60 \mathrm{~s}$ using a shovel $(0.7 \mathrm{~kg})$. In the second stage, the subjects had to mix the soil for $30 \mathrm{~s}$ with both hands while squatting down. In the third stage, the subjects used a trowel $(0.1$ $\mathrm{kg})$ to move the mixed soil into a plant container $(0.4$ $\times 1 \times 0.4 \mathrm{~m}$ ) for $90 \mathrm{~s}$. During the fourth stage, subjects planted kale seedlings (Brassica oleracea var. acephala) in the plant container $(0.4 \times 1 \times 0.4 \mathrm{~m})$ for $90 \mathrm{~s}$ while squatting down. Finally, in the fifth stage, the subjects watered the plants for $30 \mathrm{~s}$ using a watering can $(7 \mathrm{~L})$.

Garden maintenance was divided into four stages, which consisted of weeding, propping up support, removing withered leaves, and watering plants. For each activity, the subjects were expected to complete each stage within a set time. During the first stage, participants walked around the indoor garden and weeded for $90 \mathrm{~s}$ using their hands. In the second stage, the subjects affixed plants in the indoor garden to the support $(30 \mathrm{~cm})$ for $90 \mathrm{~s}$, with the use of a string $(10 \mathrm{~cm})$. In the third stage, the subjects removed withered leaves for $90 \mathrm{~s}$, and during the fourth stage, they used a watering can $(7 \mathrm{~L})$ to water the plants in the garden for $30 \mathrm{~s}$. 


\section{Measurements}

In this study, each subject wore a portable indirect calorimeter ( $\mathrm{K} 4 \mathrm{~b}^{2}$; Cosmed, Rome, Italy) when carrying out the activities. This would enable the measurement of $\mathrm{O}_{2}$ uptake and energy expenditure for the six activities and would therefore provide the MET value, which represents physical activity intensity. Subjects breathed while wearing masks throughout the test period, which enabled the measurement of $\mathrm{O}_{2}$ intake and energy consumption during each activity. Average measurements were recorded continuously at an interval of $3 \mathrm{~s}$ through a transmitter and a computer connected specifically for the test.

The value of METs was calculated by dividing $\mathrm{O}_{2}$ uptake per min $\left(\mathrm{VO}_{2}\right)$ by the value of $1 \mathrm{MET}\left(3.5 \mathrm{~mL} \cdot \mathrm{kg}^{-1} \cdot \mathrm{min}^{-1}\right)$ (Ainsworth et al., 2011), and the amount of energy consumed was calculated based on the gas exchange rate with Weir's formula (Weir, 1949).

The measuring equipment consisted of a portable unit, a receiver unit, an exercise mask, a flowmeter, battery, battery changer, and a calibration kit, among others. The portable unit (weight: $1.5 \mathrm{~kg}$ ), which collects the data, was composed of an $\mathrm{O}_{2}$ analyzer, a $\mathrm{CO}_{2}$ analyzer, sampling pump, UHF transmitter, and barometric sensors. The accuracy rate of the $\mathrm{O}_{2}$ analyzer, which enabled the measurement of $\mathrm{VO}_{2}$ and energy expenditure, was $\pm 0.02 \%$, and the response time was within $150 \mathrm{~ms}$. The $\mathrm{CO}_{2}$ analyzer allowed $\mathrm{VO}_{2}$ and $\mathrm{VCO}_{2}$ to be measured with an accuracy of $\pm 0.01 \%$ and responded within $150 \mathrm{~ms}$ (Cosmed, 2011; Parr et al., 2001).

The flowmeter measured the flow of gas per unit of time with a bidirectional turbine and an optoelectronic reader; the two were assembled together. The flowmeter measured, with an accuracy of $\pm 2 \%$, the level of ultraviolet ray blockage when the blade in the turbine revolved. This was a preparatory step before the measurement of $\mathrm{O}_{2}$ intake during each activity. During the experiment period, calibration was made for the air and standard gas $\mathrm{CO}_{2}$ : $16 \%, \mathrm{CO}_{2}: 5 \%$ ) inside the glasshouse every day prior to the first test. The analysis of the gas constituency was carried out with a $3.0 \mathrm{~L}$ syringe (Cosmed, 2011; Parr et al., 2001).

In addition, subjects wore a wristwatch and related equipment on the lower chest that recorded heart rate wirelessly through radiotelemetry (Polar T 31; FitMed, Kempele, Finland). The subjects' metabolic rate and heart rate were measured before the commencement of the six activities and during the resting periods. During the breaks, as the subjects sat on a chair in a stable position for 5 min, their metabolism rate and heart rate were measured with the Cosmed $\mathrm{K} \mathrm{b}^{2}$ and radiotelemetry (Polar $\mathrm{T}$ 31), respectively. Subjects' age and height measurements were collected through a demographic survey, while their weight and other physical characteristics were measured with a fat analyzer (Model ioi 353; Jawon Medical, South Korea).

\section{Data Analysis}

The means and standard deviations of the subjects' demographic information were calculated with Excel (Microsoft Office 2002; Microsoft Corp., Redmond, WA, USA). The 10 $\mathrm{s}$ used to walk from the resting point to the point where each activity would be carried out was deleted from the raw data prior to analysis, the result of which was indicated as the mean $\pm \mathrm{SD}$.

In order to compare the intensity of the two gardening activities and four physical activities, Duncan's multiple range test was conducted through SAS Version 9 for Windows (SAS Institute, Inc., Cary, NC, USA), with $p \leq$ 0.05 as the standard.

\section{Results}

\section{Subjects}

The study subjects were 19 male adults with an average age of $25.3 \pm 2.3$ (age range 21 to 28 years) and an average body mass index of $22.7 \pm 2.1 \mathrm{~kg} \cdot \mathrm{m}^{-2}$, which is within the normal range (Table 1 ).

\section{Metabolic Costs of Horticultural and Common Physical Activities}

After measuring the intensity of the two horticultural activities and four common physical activities among subjects, we classified the activity range as intermediate to high intensity (3.8 \pm 0.9 to $9.9 \pm 2.1$ METs) (Table 2 and Fig. 1). High-intensity activities included running $(9.9 \pm 2.1$ METs) and skipping rope (8.8 \pm 2.2 METs), whereas moderate-intensity activities included creating a vegetable bed $(5.0 \pm 1.2 \mathrm{METs})$, walking ( $4.9 \pm 0.8 \mathrm{METs})$, muscle strength exercise ( $4.5 \pm 1.3$ METs), and garden maintenance (3.8 $\pm 0.9 \mathrm{METs}$ ). We found statistically significant differences among the activities with regard to the various aspects measured in this study (i.e., METs, $\mathrm{O}_{2}$ uptake, heart rate, and energy expenditure) $(\mathrm{F}=118.31, p<0.0001)$. Creating a vegetable bed, walking, and muscle strength exercises had similar intensities, whereas garden maintenance was found to be the least intense activity among all six (Table 2 and Fig. 1). 


\section{Discussion}

This study sought to examine the physical activity intensity and energy consumption associated with two horticultural

Table 1. Descriptive characteristics of the subjects $(n=19)$ participating in a study about comparing exercise intensity between two horticultural and four common physical activities among male adults in $20 \mathrm{~s}$.

\begin{tabular}{|c|c|c|}
\hline Variable & Mean & SD \\
\hline Age (yr) & 25.8 & 2.3 \\
\hline Height $(\mathrm{cm})$ & 174.7 & 6.4 \\
\hline Body weight $(\mathrm{kg})^{\mathrm{z}}$ & 68.8 & 9.2 \\
\hline \multicolumn{3}{|l|}{ Body composition } \\
\hline Body mass index $\left(\mathrm{kg} \cdot \mathrm{m}^{-2}\right)$ & 22.7 & 2.1 \\
\hline Fat $(\mathrm{kg})^{\mathrm{z}}$ & 12.8 & 4.3 \\
\hline Lean $(\mathrm{kg})^{\mathrm{z}}$ & 53.1 & 5.2 \\
\hline Percent fat $(\%)^{\mathrm{z}}$ & 18.0 & 4.9 \\
\hline \multicolumn{3}{|l|}{ Resting metabolic rate ${ }^{\mathrm{y}}$} \\
\hline $\mathrm{VO}_{2}\left(\mathrm{~mL} \cdot \mathrm{kg}^{-1} \cdot \mathrm{min}^{-1}\right)$ & 5.3 & 1.2 \\
\hline Energy expenditure $\left(\mathrm{kJ} \cdot \mathrm{kg}^{-1} \cdot \mathrm{h}^{-1}\right)$ & 6.5 & 1.4 \\
\hline Resting metabolic equivalents (METs) & 1.5 & 0.4 \\
\hline Resting heart rate (HR) (beats $/ \mathrm{min})^{\mathrm{x}}$ & 79.3 & 4.3 \\
\hline Age-adjusted maximum HR (beats/min) ${ }^{\mathrm{w}}$ & 189.9 & 1.6 \\
\hline
\end{tabular}

${ }^{2}$ Measured using a body fat analyzer (ioi 353).

${ }^{\mathrm{y}}$ Measured using a portable calorimetric instrument $\left(\mathrm{K} \mathrm{b}^{2}\right)$ as each subject sat quietly in a chair for $5 \mathrm{~min}$.

${ }^{\mathrm{x}}$ Measured using a radiotelemetry monitor (Polar T 31) as each subject sat quietly in a chair for $5 \mathrm{~min}$.

${ }^{\mathrm{w}}$ Age-adjusted maximum heart rate $(\mathrm{HRmax})=208-0.7 \times$ age (Tanaka et al., 2001). activities and four physical activities as performed by 19 males in their twenties (mean $25.8 \pm 2.3$ years old). The physical activities ranged from intermediate to high intensity (3.8 \pm 0.9 to $9.9 \pm 2.1$ METs) (Table 2 and Fig. 1).

Running and skipping rope, which required the use of the whole body and involved dynamic movements, had a higher intensity and energy consumption than did other activities (Table 2 and Fig. 1). In a previous study, the results for running at a speed of $8.37 \mathrm{~km} \cdot \mathrm{h}^{-1}, 9.66 \mathrm{~km} \cdot \mathrm{h}^{-1}$, and $11.27 \mathrm{~km} \cdot \mathrm{h}^{-1}$ were $9.0,10.0$, and 11.5 METs, respectively, among adults aged 18 to 65 years old (Ainsworth et al., 2000). In the current study, the subjects' average speed was $8.64 \mathrm{~km} \cdot \mathrm{h}^{-1}$, with an intensity of $9.9 \pm 2.1$ METs; this result is similar to that of Ainsworth et al. (2000).

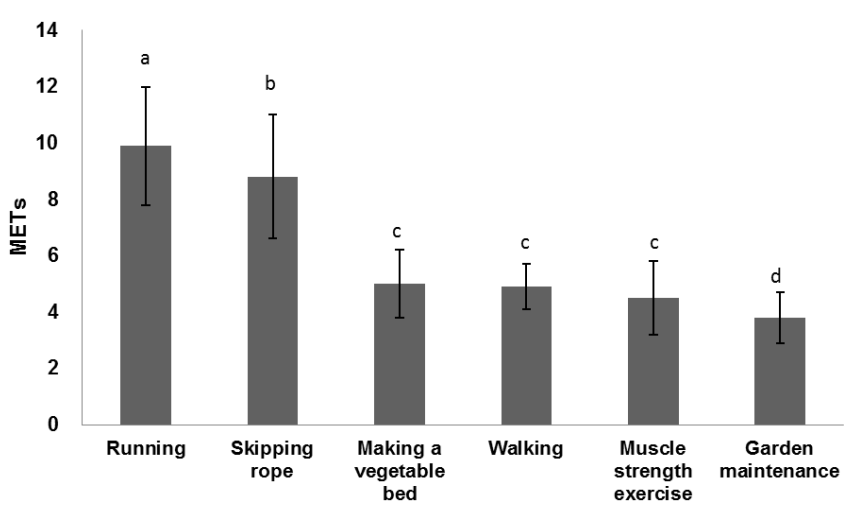

Fig. 1. Metabolic equivalents (METs) of horticultural and common physical activities in subjects in a study about comparing exercise intensity between two horticultural and four common physical activities among male adults in 20s. The data presented are means \pm SD $(n=19)$. Means with the same letter did not differ significantly according to Duncan's multiple range test, at a significance level of $p \leq 0.05$.

Table 2. Metabolic results of horticultural and common physical activities in subjects in a study about comparing exercise intensity between two horticultural and four common physical activities among male adults in 20s ( $\mathrm{n}=19$ ).

\begin{tabular}{lccc}
\hline \multirow{2}{*}{ Activity } & \multicolumn{3}{c}{ Mean (SD) } \\
\cline { 2 - 4 } & $\begin{array}{c}\mathrm{O}_{2} \text { uptake } \\
\left(\mathrm{mL} \cdot \mathrm{kg}^{-1} \cdot \mathrm{min}^{-1}\right)\end{array}$ & $\begin{array}{c}\text { Heart rate } \\
(\text { beats } / \mathrm{min})\end{array}$ & $\begin{array}{c}\text { Energy expenditure } \\
\left(\mathrm{kJ}^{\mathrm{z}} \cdot \mathrm{kg}^{-1} \cdot \mathrm{h}^{-1}\right)\end{array}$ \\
\hline Running & $35.0(4.1) \mathrm{a}$ & $149.5(19.6) \mathrm{a}$ & $42.8(5.0) \mathrm{a}$ \\
Skipping rope & $30.9(4.9) \mathrm{b}$ & $148.9(20.8) \mathrm{a}$ & $38.8(6.1) \mathrm{b}$ \\
Making a vegetable bed & $17.5(2.9) \mathrm{c}$ & $115.9(11.8) \mathrm{b}$ & $21.4(3.5) \mathrm{c}$ \\
Walking & $16.6(3.0) \mathrm{c}$ & $109.6(5.3) \mathrm{bc}$ & $20.5(3.3) \mathrm{c}$ \\
Muscle strength exercise & $15.7(3.0) \mathrm{c}$ & $117.0(12.7) \mathrm{b}$ & $19.9(3.8) \mathrm{c}$ \\
Garden maintenance & $13.5(2.7) \mathrm{d}$ & $102.9(7.8) \mathrm{c}$ & $16.4(3.1) \mathrm{d}$ \\
\hline
\end{tabular}

${ }^{\mathrm{z}} \mathrm{VO}_{2}$.

${ }^{\mathrm{y}}$ Means with the same letter within a column did not differ significantly according to Duncan's multiple range test, at a significance level of $p \leq 0.05$. 
In the United States, a study investigating skipping rope among 19 males in their twenties (mean age: $24.7 \pm 3.4$ years, weights: $73.7 \pm 9.7 \mathrm{~kg}$ ) found that skipping at 125 skip/min (11.7 METs), 135 skip/min (11.8 METs), and 145 skip/min (11.7 METs) were all high intensity (Town et al., 1980). Skipping ropes at $102 \mathrm{skip} / \mathrm{min}$ was also a high-intensity activity (11.9 METs). In the current study, we also found that skipping ropes at $102 \mathrm{skip} \cdot \mathrm{min}^{-1}$ (8.8 \pm 2.2 METs) was a high-intensity activity, even though it was slightly lower in terms of METs than it was in previous studies. It is reasonable that skipping rope is a high-intensity activity, as the concentrated use of muscles in the same area during repetitive jumps requires high energy consumption (Jette et al., 1979).

High-intensity physical activities such as skipping rope and running are more effective than low- to moderate-intensity activities in enhancing aerobic capacity, weight adjustment, and decreasing obesity, which are all important for the improvement of cardiovascular health (Braith et al., 1994; Doucet et al., 1999; King et al., 1995b; Swain, 2005; Swain and Franklin, 2002, 2006; Tremblay et al., 1994; Yoshioka et al., 2001). In addition, it is reported that an exercise program consisting of intermittent high-intensity exercises had more effective health benefits than did low-intensity exercise carried out over a long period (Hunter et al., 1998). To ensure that individuals meet the recommended amount of exercise for adults, individuals should combine moderateand high-intensity activities (Haskell et al., 2007). Therefore, when developing a gardening program aimed at improving health, rather than simply engaging in low- to moderateintensity gardening activities, high-intensity gardening activities such as digging [6.3 \pm 1.2 METs (Park et al., 2014a), $6.6 \pm 1.6$ METs (Park et al., 2014c)] and raking [6.2 \pm 1.5 METs (Park et al., 2014c)] should be intermittently combined as part of the gardening program.

Creating a vegetable bed, walking, muscle strength exercises, and garden maintenance were found to be of low to moderate intensity, as compared to running and skipping rope. According to Ainsworth et al. (2000), for adults aged 18-65, walking at a speed of $5.63 \mathrm{~km} \cdot \mathrm{h}^{-1}$ and a very brisk pace of $6.44 \mathrm{~km} \cdot \mathrm{h}^{-1}$, respectively, constituted moderateintensity activities, at 3.8 and 5.0 METs, respectively. In this study on male adults in their twenties, walking at a speed of $5.79 \mathrm{~km} \cdot \mathrm{h}^{-1}$ was also found to be a moderateintensity activity, at $4.9 \pm 0.8$ METs. When compared to walking at $5.63 \mathrm{~km} \cdot \mathrm{h}^{-1}$ (3.8 METs) among adults between 18 and 65 years, the MET value of walking at $5.80 \mathrm{~km} \cdot \mathrm{h}^{-1}$ among adults in their twenties was slightly higher; this points to a difference in activity intensity by age. Groups of older individuals tended to obtain a higher mean MET value than younger age groups (Harrell et al., 2005). Therefore, the only slightly higher METs value in this study, relative to previous studies, could be attributed to older subjects (aged 18 to 65 years) were used in Ainsworth et al. (2000). In a study on 25 male and female adults aged 30-50, walking intensity was found to vary in intensity according to speed, with moderate $\left(94.7 \mathrm{~m} \cdot \mathrm{min}^{-1}\right)$ and brisk $\left(111.2 \mathrm{~m} \cdot \mathrm{min}^{-1}\right)$ paces at $4.09 \pm 0.85$ and $5.59 \pm$ 1.09 METs, respectively (Hendelman et al., 2000). In the current study, the walking pace of participants was similar to walking at a speed of $96 \mathrm{~m} \cdot \mathrm{min}^{-1}$, with an intensity of $4.9 \pm 0.8$ METs.

Ainsworth et al. (2000) results indicated 3.0 METs for light to moderate weight resistance exercises and 8.0 METs for a vigorous level of weight resistance exercises, depending on the weight of the dumbbell or weight. Muscle strength exercises (i.e., weight lifting) are forms of resistance exercises. Miyachi et al. (2010) conducted a study on 12 adults (7 males, 5 females) aged 22-44 years, measuring the intensity of the Wii Fit Plus video game, in which players had to follow the various motions in balance exercises, yoga, and resistance exercises on a force plate. These authors found 15 resistance exercises, including squats, as well as lunge and single leg extension exercises to be moderate-intensity activities, at $3.2 \pm 1.2$ METs. The muscle strength exercise intensity ( $4.5 \pm 1.3 \mathrm{METs})$ in the current study, wherein subjects carried out squats, a dumbbell row, and a lateral raise for $5 \mathrm{~min}$ while holding dumbbells weighing $1 \mathrm{~kg}$ in each hand (constituting lightweight resistance), seemed slightly high, but all were in the range of moderate-intensity exercise.

In a previous study, 10 gardening activities, such as digging, raking, weeding, and planting seedlings, were considered moderate- to high-intensity activities (3.5 \pm 0.5 to $6.3 \pm 1.2$ METs) for adults in their twenties (Park et al., 2014a). In the current study, creating a vegetable bed involved digging ( $6.9 \pm 0.7 \mathrm{METs}$ ), indicated as a highintensity activity by Park et al. (2014a), and moderateintensity activities such as mixing growing media (3.9 \pm 0.7 METs) and plant transplants (3.6 \pm 0.4 METs). In addition, garden maintenance consisted of moderate-intensity activities such as weeding (5.2 \pm 0.7 METs), harvesting ( $4.3 \pm 0.5 \mathrm{METs})$, and watering ( $4.0 \pm 0.5 \mathrm{METs})$. Therefore, gardening activities were regarded as moderate-intensity activities.

In previous studies, for elderly individuals aged more than 65 years, making a vegetable bed was considered, overall, a moderate-intensity activity (3.6 $\pm 0.7 \mathrm{METs})$ that 
consisted of moderate-intensity sub-activities (Park et al., 2014b), such as digging ( $4.5 \pm 0.7$ METs), as well as low-intensity sub-activities, such as mixing soil $(2.4 \pm 0.7$ METs) and transplanting plants $(2.9 \pm 0.9$ METs) (Park et al., 2011). Maintaining a garden is also a moderateintensity activity ( $3.4 \pm 0.6$ METs) composed of low- to moderate-intensity sub-activities (Park et al., 2014b) such as weeding (3.4 $\pm 0.6 \mathrm{METs})$, harvesting produce $(2.7 \pm 0.6$ METs), and watering with a watering can (2.8 \pm 0.9 METs) (Park et al., 2011). Furthermore, a garden establishment program for children aged 11-13 years, similar to Park et al. (2014c) study, was composed of high-intensity activities such as digging (6.6 $\pm 1.6 \mathrm{METs}$ ) and raking (6.2 $\pm 1.5 \mathrm{METs}$ ), and moderate-intensity activities such as transplanting plants ( $4.3 \pm 0.5 \mathrm{METs})$ and watering ( $4.6 \pm 1.1 \mathrm{METs})$; the latter were carried out for a total of $10 \mathrm{~min}$.

Previous studies found that elderly gardeners met physical activity recommendations, as shown by their overall physical condition, such as gripping power, pinching force, and overall physical function. These findings provide evidence that, as a form of physical activity, gardening activities offer various physical benefits (Park et al., 2009). Individuals can engage in these types of moderate-intensity exercises on their own, as they require less guidance or supervision from experts (Blair and Connelly, 1996). Further, the exercise has the added advantage of posing a low risk of injury (ACSM, 1995).

An investigation into the injury rate due to physical activities has revealed that running and muscle strength exercise pose high injury risks, whereas walking and gardening pose a relatively low injury risk. Injury due to physical activities is detrimental to individuals' participation in the same. Therefore, engaging in activities that pose a lower risk of injury, such as walking and gardening, is recommended (Pons-Villanueva et al., 2010; Powell et al., 1998). It is worth noting that gardening activities also include walking movement. Based on the observation of gardening activities by elderly individuals aged 63-86 years, walking was found to account for $58.8 \%$ of overall gardening activities (Park and Shoemaker, 2009). Therefore, gardening is an outdoor physical activity with a high potential for facilitating the maintenance of a physically active lifestyle (Park et al., 2009; Van den Berg et al., 2010).

Based on research on muscle use during gardening activities (e.g., weeding, hoeing), researchers used electromyography patches to identify the overall muscular activity for gardening, which scanned 16 areas of the body (Park et al., 2014d). Moreover, Turner et al. (2002) proposed that gardening activities such as weeding and digging require the use of the entire body, and that this has a positive impact on subjects' bone density.

Community gardening consists of group activities, which enable participation in enjoyable work and continuous interaction with neighbors. Support networks (Alaimo et al., 2005; Armstrong, 2000; Been and Voicu, 2006), formed when participants meet and share their experiences, become a key motivator in individuals' continuing participation in gardening activities (Allender et al., 2006; Arthur and Finch 1999).

Furthermore, gardening activities tend to vary according to plants' growth cycle and seasonal changes (Park et al., 2008b). This allows participants to predict, plan, and directly engage in various gardening activities necessary for each particular period (Lekies and Sheavly, 2007). This further enables autonomous and regular physical activities among participants. Further, observing plants growing could be interesting enough to motivate individuals to engage in gardening as a form of physical activity (Deci and Ryan, 1995; Park et al., 2008b).

In summary, this study demonstrated the applicability of gardening as a physical activity for health benefits. Horticultural activities can be considered a moderate- to high-intensity exercise involving the whole body, as well as a form of physical activity that could spark motivation. According to the current research results, health benefits such as increased aerobic capacity and muscle strength could be obtained through gardening activities, which consists of moderate-intensity activities such as walking and muscle strength exercises (i.e., weight lifting). Compared to other physical activities, gardening activities are unique in that they carry relatively low injury risks and involve plant life. These render gardening an interesting physical activity, which not only meets the recommended intensity but also is safe. Furthermore, the behavioral elements particular to gardening activities, such as the establishment of social networks as a result of collaboration, autonomy of activities, interest, and joy, can provide intrinsic motivation, such that people might find it rather easy to continue engaging in gardening activities compared with other exercises.

The results of this study lend information towards devising horticultural activity programs based on activity intensity as well as physical activity programs designed to change adults' physical activity patterns, with the aim of preventing sedentary lifestyles. It would be interesting to determine the health benefits of a long-term horticultural activity intervention or compare the health benefits of a horticultural activity and other common physical activity programs. The application of horticultural activity program based on the 
research data such as exercise intensities of horticultural activities may contribute to exploring the therapeutic mechanisms of horticultural activities as an intervention in future. Future study needs to investigate the differences of metabolic costs according to gender and age differences.

\section{Literature Cited}

Ainsworth, B.E., W.L. Haskell, M.C. Whitt, M.L. Irwin, A.M. Swartz, S.J. Strath, W.L. O’Brien, D.R. Bassett, K.H. Schmitz, P.O. Emplaincourt, D.R. Jacobs, and A.S. Leon. 2000. Compendium of physical activities: An update of activity codes and MET intensities. Med. Sci. Sports Exercise 32:S498-S504.

Ainsworth, B.E., W.L. Haskell, S.D. Herrmann, N. Meckes, D.R. Bassett, Jr., C. Tudor-Locke, J.L. Greer, J. Vezina, M.C. WhittGlover, and A.S. Leon. 2011. 2011 compendium of physical activities: A second update of codes and MET values. Med. Sci. Sports Exercise 43:1575-1581.

American College of Sports Medicine (ACSM). 1995. ACSM's guidelines for exercise testing and prescription. Lea \& Febiger, Philadelphia.

Alaimo, K., T.M. Reischl, A. Atkinson, and P. Hutchison. 2005. We don't only grow vegetables, we grow values, p. 123-142. In: D. Brugge and P. Hynes (eds.). Neighborhood benefits of community gardens in Flint, Michigan. Ashgate Publishing Ltd., Aldershot.

Allender, S., G. Cowburn, and C. Foster. 2006. Understanding participation in sport and physical activity among children and adults: A review of qualitative studies. Health Educ. Res. 21:826-835.

Armstrong, D. 2000. A survey of community gardens in upstate New York: Implications for health promotion and community development. Health Place 6:319-327.

Arthur, S. and H. Finch. 1999. Physical activity in our lives: Qualitative research among disabled people. Health Educ. Authority, London.

Atwood, C. 2004. Ergonomic of leisure activities, p. 419-433. In: M. Sanders (ed.). Ergonomics and the management of musculoskeletal disorders. Elsevier, St. Louis, MO.

Bassett, D.R., B.E. Ainsworth, A.M. Swartz, S.J. Strath, W.L. O'Brien, and G.A. King. 2000. Validity of four motion sensors in measuring moderate intensity physical activity. Medicine Sci. Sports Exercise 32:S471-S480.

Been, V. and I. Voicu. 2006. The effect of community gardens on neighboring property values, no. 06-09. NYU Center for Law and Economics, New York Univ., School of Law, NY.

Biddle, S.J.H. 1995. Exercise motivation across the lifespan, p. 5-25. In: S.J.H. Biddle (ed.). European perspectives on exercise and sport psychology. Human Kinetics Publ., Champaign, IL.

Blair, S.N. and J.C. Connelly. 1996. How much physical activity should we do? The case for moderate amounts and intensities of physical activity. Res. Quarterly Exercise Sport 67:193-205.
Braith, R.W., M.L. Pollock, D.T. Lowenthal, J.E. Graves, and M.C. Limacher. 1994. Moderate and high intensity exercise lowers blood pressure in normotensive subjects 60 to 79 years of age. Amer. J. Cardiolgy 73:1124-1128.

Brownson, R.C., R.A. Housemann, D.R. Brown, J.J. Thompson, A.C. King, B.R. Malone, and J.F. Sallis. 2000. Promoting physical activity in rural communities: Walking trail access, use, and effects. Amer. J. Preventive Medicine 18:235-241.

Brooks, A.G., R.T. Withers, C.J. Gore, A.J. Vogler, J. Plummer, and J. Cormack. 2004. Measurement and prediction of METs during household activities in 35- to 45-year-old females. European J. Appl. Physiol. 91:638-648.

Calfas, K.J., J.F. Sallis, J.F. Nichols, A.J. Sarkin, M.F. Johnson, S. Caparosa, S. Thompson, C.A. Gehrman, and J.E. Alcaraz. 2000. Project GRAD: Two year outcomes of a randomized controlled physical activity intervention among young adults. Amer. J. Preventive Medicine 18:28-36.

Cammack, C., T.M. Waliczek, and J.M. Zajicek. 2002. The green brigade: The psychological effects of a community-based horticultural program on the self-development characteristics of juvenile offenders. HortTechnology 12:82-86.

Caspersen, C.J., K.E. Powell, and G.M. Christenson. 1985. Physical activity, exercise, and physical fitness: Definitions and distinctions for health-related research. Public health Rpt. 100:126-131.

Caspersen, C.J., M.A. Pereira, and K.M. Curran. 2000. Changes in physical activity patterns in the United States, by sex and cross-sectional age. Medicine Sci. Sports Exercise 32:1601-1609. Cosmed. 2011. K4b ${ }^{2}$ user manual. 22nd ed. COSMED Srl, Rome.

Deci, E.L. and R.M. Ryan. 1995. Efficacy, agency, and self-esteem. Plenum Press, NY.

Dickinson, J., S. Duma, H. Paulsen, L. Rilveria, J. Twiss, and T. Weinman. 2003. Community gardens: Lessons learned from California healthy cities and communities. Amer. J. Public Health 93:1435-1438.

Doucet, E., P. Imbeault, N. Almeras, and A. Tremblay. 1999. Physical activity and low-fat diet: Is it enough to maintain weight stability in the reduced-obese individual following weight loss by drug therapy and energy restriction? Obesity Res. 7:323-333.

Doyle, R. and M.E. Krasny. 2003. Participatory rural appraisal as an approach to environmental education in urban community gardens. Environmental Educ. Res. 9:91-115.

Ferris, J., C. Norman, and J. Sempik. 2001. People, land, and sustainability: Community gardens and the social dimension of sustainable development. Social Policy Administration 35: 559-568.

Fusco, D. 2001. Creating relevant science through urban planning and gardening. J. Res. Sci. Teaching 38:860-877.

Gunn, S.M., A.G. Brooks, R.T. Withers, C.J. Gore, N. Owen, M.L. Booth, and A.E. Bauman. 2002. Determining energy expenditure during some household and garden tasks. J. Medicine Sci. Sports Exercise 34:895-902. 
Gunn, S.M., G.E. Van der Ploeg, R.T. Withers, C.J. Gore, N. Owen, A.E. Bauman, and J. Cormack. 2004. Measurement and prediction of energy expenditure in male during household and garden tasks. European J. Appl. Physiol. 91:61-70.

Hallal, P.C., L.B. Andersen, F.C. Bull, R. Guthold, W. Haskell, and U. Ekelund. 2012. Global physical activity levels: Surveillance progress, pitfalls, and prospects. Lancet 38:247-257.

Harrell, J.S., R.G. McMurray, C.D. Baggett, M.L. Pennell, P.F. Pearce, and S.I. Bangdiwala. 2005. Energy costs of physical activities in children and adolescents. Medicine Sci. Sports Exercise 37:329-336.

Haskell, W.L., I.M. Lee, R.R. Pate, K.E. Powell, S.N. Blair, B.A. Franklin, C.A. Macera, G.W. Heath, P.D. Thompson, and A, Bauman. 2007. Physical activity and public health: Updated recommendation for adults from the American College of Sports Medicine and the American Heart Association. Medicine Sci. Sports Exercise 39:1423-1434.

Hendelman, D., K. Miller, C. Baggett, E. Debold, and P. Freedson. 2000. Validity of accelerometry for the assessment of moderate intensity physical activity in the field. Medicine Sci. Sports Exercise 32:S442-S429.

Holland, L. 2004. Diversity and connections in community gardens: A contribution to local sustainability. Local Environ. 9:285-305.

Hunter, G.R., R.L. Weinsier, M.M. Bamman, and D.E. Larson. 1998. A role for high intensity exercise on energy balance and weight control. Intl. J. Obesity 22:489-493.

Irvine, S., L. Johnson, and K. Peters. 1999. Community gardens and sustainable land use planning: A case-study of the Alex Wilson Community Garden. Local Environ. 4:33-46.

Jette, M., K. Sidney, and G. Blumchen. 1990. Metabolic equivalents (METS) in exercise testing, exercise prescription, and evaluation of functional capacity. Clinical Cardiology 13:555-565.

Jette, M., J. Mongeon, and R. Routhier. 1979. The energy cost of rope skipping. J. Sports Medicine 19:33-37.

Kaplan, R. 1973. Some psychological benefits of gardening. Environ. Behavior 5:145-162.

King, A.C., W.L. Haskell, D.R. Young, R.K. Oka, and M.L. Stefanick. 1995a. Long-term effects of varying intensities and formats of physical activity on participation rates, fitness, and lipoproteins in men and women aged 50 to 65 years. Circulation 91:2596-2604.

King, A.C., R.W. Jeffery, F. Fridinger, L. Dusenbury, S. Provence, S.A. Hedlund, and K. Spangler. 1995b. Environmental and policy approaches to cardiovascular disease prevention through physical activity: Issues and opportunities. Health Educ. Behavior 22: 499-511.

Kilpatrick, M., E. Hebert, and E. Jacobsen. 2002. Physical activity motivation: A practitioner's guide to self-determination theory. J. Phys. Educ. Recreation Dance 73(4):36-41.

Kingsley, J.Y., M. Townsend, and C. Henderson-Wilson. 2009. Cultivating health and wellbeing: Members' perceptions of the health benefits of a Port Melbourne community garden. Leisure
Studies 28:207-219.

Lekies, K.S. and M.E. Sheavly. 2007. Fostering children's interests in gardening. Appl. Environmental Educ. Commun. 6:67-75.

Leslie, E., M.J. Fotheringham, N. Owen, and A. Bauman. 2001. Age-related differences in physical activity levels of young adults. Medicine Sci. Sports Exercise 33:255-258.

Mein, G.K., M.J. Shipley, M. Hillsdon, G.T.H. Ellison, and M.G. Marmot. 2005. Work, retirement and physical activity: Crosssectional analyses from the Whitehall II study. European J. Public Health 15:317-322.

Miyachi, M., K. Yamamoto, K. Ohkawara, and S. Tanaka. 2010. METs in adults while playing active video games: A metabolic chamber study. Medicine Sci. Sports Exercise 42:1149-1153.

National Association for Sport and Physical Education (NASPE). 2003. Adults/teens attitudes toward physical activity and physical education. Sports J. p. 6.

Park, S.A., A.Y. Lee, K.S. Lee, and K.C. Son. 2014a. Gardening tasks performed by adults are moderate- to high-intensity physical activities. HortTechnology 24:1-6.

Park S.A., J.Y. Lee, K.S. Lee, and K.C. Son. 2014b. Metabolic costs of daily activities in community dwelling older adults. Intl. J. Gerontology 8:228-229.

Park, S.A., A.Y. Lee, K.S. Lee, and K.C. Son. 2014c. Comparison of the metabolic costs of gardening and common physical activities in children. Kor. J. Hort. Sci. Technol. 32:123-128.

Park S.A., A.Y. Lee, J.J. Kim, K.S. Lee, J.M. So, and K.C. Son. 2014d. Electromyographic analysis of upper and lower limbs muscles during gardening tasks. Kor. J. Hort. Sci. Technol. 32:710-720.

Park, S.A. and C.A. Shoemaker. 2009. Observing body position of older adults while gardening for health benefits and risks. Activities Adaptation Aging 33:31-38.

Park, S.A., C.A. Shoemaker, and M.D. Haub. 2008a. A preliminary investigation on exercise intensities of gardening tasks in older adults. Perceptual Motor Skills 107:974-980.

Park, S.A, C.A. Shoemaker, and M.D. Haub. 2008b. Can older gardeners meet the physical activity recommendation through gardening? HortTechnology 18:639-643.

Park, S.A., C.A. Shoemaker, and M.D. Haub. 2009. 1980/01Physical and psychological health conditions of older adults classified as gardeners or nongardeners. HortScience 44:206-210.

Park, S.A., H.S. Lee, K.S. Lee, K.C. Son, and C.A. Shoemaker. 2013. The metabolic costs of gardening tasks in children. HortTechnology 23:589-594.

Park, S.A., K.S. Lee, and K.C. Son. 2011. Determining exercise intensities of gardening tasks as a physical activity using metabolic equivalents in older adults. HortScience 46:1706-1710.

Park, S.A., K.S. Lee, K.C. Son, and C.A. Shoemaker. 2012. Metabolic cost of horticulture activities in older adults. J. Jpn. Soc. Hot. Sci. 81:295-299.

Parr, B.B., S.J. Strath, D.R. Bassett, Jr. and E.T. Howley. 2001. Validation of the Cosmed $\mathrm{K} 4 \mathrm{~b}^{2}$ portable metabolic measurement 
system. Med. Sci. Sports Exercise 33:S300.

Pate, R.R., J.R. O'Neill, and F. Lobelo. 2008. The evolving definition of sedentary. Exercise Sport Sci. Rev. 36:173-178.

Patel, I.C. 1991. Gardening's socioeconomic impacts: Community gardening in an urban setting. J. Extension 29(4):7-8.

Pons-Villanueva, J., M. Seguí-Gómez, and M.A. Martínez-González. 2010. Risk of injury according to participation in specific physical activities: A 6-year follow-up of 14356 participants of the SUN cohort. Intl. J. Epidemiology Community Health 39:580-587.

Popham, F. and R. Mitchell. 2006. Leisure time exercise and personal circumstances in the working age population: longitudinal analysis of the British household panel survey. Intl. J. Epidemiology Community Health 60:270-274.

Powell, K.E., G.W. Heath, M.J. Kresnow, J.J. Sacks, and C.M. Branche. 1998. Injury rates from walking, gardening, weightlifting, outdoor bicycling, and aerobics. Med. Sci. Sports Exercise 30:1246-1249.

Powell, K.E., E.P. Amanda, and N.B. Steven. 2011. Physical activity for health: What kind? How much? How intense? On top of what? Public Health 32:349-365.

Powers, S.K. and E.T. Howley. 2007. Exercise physiology: Theory and application to fitness and performance. McGraw-Hill College, NY.

Reynolds, V. 1999. The Green Gym: An evaluation of a pilot project in Sonning Common, Oxfordshire, Report no. 8. Oxford Brookes Univ., Oxford.

Reynolds, V. 2002. Well-being comes naturally: An evaluation of the BTCV Green Gym at Portslade, East Sussex, Report no.17. Oxford Brookes Univ., Oxford.

Rural Development Administration (RDA). 2010. Actual condition and consciousness for urban agriculture. Natl. Acad. Agr. Sci., Suwon, Korea.

Sallis, J.F., A. Bauman, and M. Pratt. 1998. Environmental and policy interventions to promote physical activity. Amer. J. Preventive Medicine 15:379-397.

Schmid, T.L., M. Pratt, and E. Howze. 1995. Policy as intervention: Environmental and policy approaches to the prevention of cardiovascular diseases. Amer. J. Public Health 85:1207-1211.

Stone, E.J., T.L. McKenzie, G.J. Welk, and M. Booth. 1998. Effects of physical activity interventions in youth: Review and synthesis. Amer. J. Preventive. Medicine 15:298-315.

Swain, D.P. 2005. Moderate or vigorous intensity exercise: Which is better for improving aerobic fitness? Preventive Cardiology 8:55-58.

Swain, D.P. and B.A. Franklin. 2002. $\mathrm{VO}_{2}$ reserve and the minimal intensity for improving cardiorespiratory fitness. Med. Sci. Sports Exercise 34:152-157.

Swain, D.P. and B.A. Franklin. 2006. Comparison of cardioprotective benefits of vigorous versus moderate intensity aerobic exercise. J. Amer. Cardiology 97:141-147.

Tanaka, H., K.D. Monahan, and D.R. Seals. 2001. Age-predicted maximal heart rate revisited. J. Amer. College Cardiology 37:153-156.

Town, G.P., N. Sol, and W.E. Sinning. 1980. The effect of rope skipping rate on energy expenditure of males and females. Med. Sci. Sports Exercise 12:295-298.

Tremblay, A., J.A. Simoneau, and C. Bouchard. 1994. Impact of exercise intensity on body fatness and skeletal muscle metabolism. Metabolism 43:814-818.

Turner, L.W., M.A. Bass, L. Ting, and B. Brown. 2002. Influence of yard work and weight training on bone mineral density among older U.S. women. J. Women Aging 14:139-148.

U.S. Department of Health and Human Service (HSS). 2008a. Physical activity guidelines advisory committee report, 2008. HHS, Washington D.C. A1-H14.

U.S. Department of Health and Human Services. 2008b. Physical activity guidelines for Americans. Available at: http://www. health.gov/paguidelines/pdf/paguide.pdf.

Van den Berg, A.E., M. van Winsum-Westra, S. De Vries, and S.M. Van Dillen. 2010. Allotment gardening and health: A comparative survey among allotment gardeners and their neighbors without an allotment. Environ. Health 9:74.

Waliczek, T.M., J.M. Zajicek, and R.D. Lineberger. 2005. The influence of gardening activities on consumer perceptions of life satisfaction. HortScience 40:1360-1365.

Walsh, J.M.E., A.R. Pressman, J.A. Cauley, and W.S. Browner. 2001. Predictors of physical activity in community-dwelling elderly white women. J. Gen. Internal Medicine 16:721-727.

Warburton, D.E.R., C.W. Nicol, and S.S.D. Bredin. 2006. Health benefits of physical activity: The evidence. Can. Medical Assn. J. 174:801-809.

Warren, T.Y., V. Barry, S.P. Hooker, X. Sui, T. Church, and S.N. Blair. 2010. Sedentary behaviors increase risk of cardiovascular disease mortality in men. Med. Sci. Sports Exercise 42:879-885.

Weir, J.B.V. 1949. New methods for calculating metabolic rate with special reference to protein metabolism. J. Physiol. 109:1-9.

Yoshioka, M., E. Doucet, S. St-Pierre, N. AlmeÂras, D. Richard, A. Labrie, JP DespreÂs, C. Bouchard, and A. Tremblay. 2001. Impact of high-intensity exercise on energy expenditure, lipid oxidation and body fatness. Intl. J. Obesity 25:332-339. 